\title{
Article
}

\section{Copolymer\#Cyclodextrin Inclusion Complexes in Water and in the Solid State. A Physico-Chemical Study}

G. Lazzara, and S. Milioto

J. Phys. Chem. B, 2008, 112 (38), 11887-11895 • DOI: 10.1021/jp8034924 • Publication Date (Web): 27 August 2008

Downloaded from http://pubs.acs.org on November 18, 2008

\section{More About This Article}

Additional resources and features associated with this article are available within the HTML version:

- $\quad$ Supporting Information

- $\quad$ Access to high resolution figures

- $\quad$ Links to articles and content related to this article

- $\quad$ Copyright permission to reproduce figures and/or text from this article

\section{View the Full Text HTML}




\title{
Copolymer-Cyclodextrin Inclusion Complexes in Water and in the Solid State. A Physico-Chemical Study
}

\author{
G. Lazzara* and S. Milioto \\ Dipartimento di Chimica Fisica "F. Accascina", Università degli Studi di Palermo, Viale delle Scienze, \\ Parco D'Orleans II, 90128 Palermo, Italy
}

Received: April 22, 2008; Revised Manuscript Received: June 18, 2008

\begin{abstract}
The formation of inclusion complexes (ICs) composed of cyclodextrins (CDs) and poly(ethylene oxides) - poly(propylene oxides)-poly(ethylene oxides) (PEO-PPO-PEO) was studied. To this purpose, native and hydroxypropyl cyclodextrins with different cavity size were chosen. The PEO-PPO-PEO copolymers were selected to study the role of the molecular weight, keeping constant the hydrophilic/ hydrophobic ratio, and the hydrophilicity. The volumetric studies at $25^{\circ} \mathrm{C}$ allowed to determine the equilibrium constant and the volume change for the IC formation in water as well as the IC stoichiometry. Surface tension experiments evidenced that the copolymer and the $\mathrm{CD}$ interfacial behavior is controlled by the formation of ICs taking place in the bulk phase. It was proved that the differential scanning calorimetry (DSC) is a valid method to describe quantitatively the IC in the solid state. The combination of volumes, DSC and FTIR techniques together with the geometric information highlighted the following points: (1) the included copolymer is in the amorphous state; (2) the IC composed of native CDs adopts a channel structure with two EO units incorporated into one CD molecule; (3) the IC composed of hydroxypropyl-cyclodextrin is a polymeric structure like a necklace decorated with CD rings. Finally, TGA experiments showed that the thermal stability of the IC depends on the nature of both components.
\end{abstract}

\section{Introduction}

Some years ago Harada observed that cyclodextrins (CDs) and poly(ethylene)glycol (PEG) form inclusion complexes (ICs) ${ }^{1-4}$ made up of a channel of CD molecules fitting one or more polymeric molecules ${ }^{5-7}$ (they are known as polypseudorotaxanes). Cyclodextrins are cyclic oligosaccharides the most common consisting of 6,7 , and 8 glucopyranose units linked by $\alpha-1,4$ glucosidic bonds; they are called $\alpha$-cyclodextrin $(\alpha-C D), \beta$-cyclodextrin $(\beta$-CD) and $\gamma$-cyclodextrin $(\gamma-C D)$, respectively. They present a truncated cone shape with a hydrophobic core, which can accommodate nonpolar compounds,${ }^{8-10}$ and two hydrophilic rims composed of -OH groups. The ICs formation depends on internal parameters (nature of $\mathrm{CD}$, polymer and solvent media) as well as on external parameters (temperature and pressure). The ICs are models for molecular recognition, can be employed in drug delivery ${ }^{11}$ and form hydrogels which are promising in the field of biotechnology, bioengineering, etc. Accordingly, new strategies are developed to fabricate novel supramolecular hydrogels. ${ }^{12}$

Several routes have been explored to synthesize ICs. For instance, pure PEG, at low molecular weights, and $\alpha-C D$ powder ${ }^{13}$ were mixed or $\alpha-C D$ was added to the PEG+acetone mixture. The formation of ICs was monitored in water, heavy water and urea. ${ }^{14}$ Recently, attention has been paid on ICs formed by CDs and block copolymers ${ }^{15-20}$ which offer different sites of binding and may be selectively threaded by CDs. Biodegradable copolymers, like poly( $\epsilon$-caprolactone $)-$ poly(tetrahydrofuran)-poly $(\epsilon \text {-caprolactone })^{15}$ (PCL-PTHF-PCL) and poly $(\epsilon$-caprolactone $)-$ poly(ethylene oxide $)-\operatorname{poly}(\epsilon$-caprolactone) (PCL-PEO-PCL) ${ }^{16}$ and biocompatible copolymers, ${ }^{18-20}$ like poly(ethylene oxide)-poly(propylene oxide)-poly(ethylene

\footnotetext{
*Corresponding author. E-mail: g.lazzara@unipa.it.
}

oxide) (PEO-PPO-PEO), have been investigated. The latter are commercially available under the trade name of Pluronics. Their molecular structure can be finely tuned by modulating the size of the PEO and/or the PPO blocks. They are active at the interfaces, ${ }^{21,22}$ form aggregates in aqueous solvents, ${ }^{23,24}$ combined with surfactants generate different hydrophobic structures able to solubilize additives sparingly soluble in water ${ }^{25-27}$ while combined with laponite $\mathrm{RD}^{28}$ form gels. To the best of our knowledge, only the paper of Ikeda et al. ${ }^{29}$ reports the thermodynamics of formation of aqueous ICs based on copolymers and $\alpha$-CD-based molecular tube in spite it provides insights on the driving forces of the process and tools for a rigorous prediction of the behavior of mixtures not yet studied.

To shed some light to this issue we thought it would be interesting to study from different viewpoints the ICs, formed by $\mathrm{CD}$ and $\mathrm{PEO}-\mathrm{PPO}-\mathrm{PEO}$, in water and in the solid state. The nature of both the components was systematically changed. The thermodynamics of IC formation in water was determined through volume studies and allowed the equilibrium constant and the volume change for the IC formation as well as the IC stoichiometry. Another analyzed aspect deals with the characterization of the behavior at the air/aqueous phase interface as the ICs used for drug release may play a relevant role at the biological interfaces. The ICs in the solid state were studied. Based on the knowledge ${ }^{13,30}$ that the melting peak of the polymer included into the CD disappears as a consequence of the crystallinity loss, differential scanning calorimetry studies on the solid copolymer $+\mathrm{CD}$ mixtures at various compositions were carried out and provided the stoichiometries of the ICs. Remembering that FTIR spectra of Pluronics ${ }^{31}$ present bands specific of the crystalline and amorphous states of the copolymer, some FTIR spectra were also determined to evidence the presence of ICs. Finally, the thermal stability of the ICs was checked by means of thermogravimetric experiments. 
TABLE 1: Structure and Molecular Weight of Triblock Copolymers Used in the Experiments ${ }^{a}$

\begin{tabular}{lccr}
\hline \multicolumn{1}{c}{ structure } & abbreviation & $\mathrm{EO} / \mathrm{PO}$ & $M W_{\mathrm{p}}$ \\
\hline $\mathrm{EO}_{13} \mathrm{PO}_{30} \mathrm{EO}_{13}$ & $\mathrm{~L} 64$ & 0.66 & 2900 \\
$\mathrm{EO}_{76} \mathrm{PO}_{29} \mathrm{EO}_{76}$ & $\mathrm{~F} 68$ & 4.0 & 8400 \\
$\mathrm{EO}_{103} \mathrm{PO}_{39} \mathrm{EO}_{103}$ & $\mathrm{~F} 88$ & 4.0 & 11400 \\
$\mathrm{EO}_{132} \mathrm{PO}_{50} \mathrm{EO}_{132}$ & F108 & 4.0 & 14600 \\
$\mathrm{EO}_{98} \mathrm{PO}_{67} \mathrm{EO}_{98}$ & $\mathrm{~F} 127$ & 2.2 & 12600
\end{tabular}

${ }^{a}$ Units are as follows: EO/PO, g/g; $M W_{\mathrm{p}}, \mathrm{g} \mathrm{mol}^{-1}$.

\section{Materials and Methods}

Cyclodextrins (CDs) are Aldrich products with the exception of hydroxypropyl- $\beta$-cyclodextrin (HP- $\beta$-CD) with the averaged substitution degree for each glucopyranosidic unit (MS) of 0.43 (Acros). Other CDs are $\alpha$-cyclodextrin $(\alpha-C D), \beta$-cyclodextrin $(\beta$-CD), hydroxypropyl- $\alpha$-cyclodextrin (HP- $\alpha-C D)$ and hydroxypropyl- $\gamma$-cyclodextrin (HP- $\gamma$-CD), both having MS $=0.6 . \alpha$-DGlucose is from Aldrich $(>98 \%)$. The polyethylene glycol homopolymers PEG 900 and PEG 1500 are Fluka products. The studied block copolymers (BASF) are (ethylene oxide) ${ }_{a}-$ (propylene oxide $)_{b}-(\text { ethylene oxide })_{a}$ represented in Table 1 as $\mathrm{EO}_{a} \mathrm{PO}_{b} \mathrm{EO}_{a}$ where $a$ and $b$ indicate the repetitive number of $\mathrm{EO}$ and PO units, respectively. The polydispersity indices $(1.1-1.2)$ were determined ${ }^{32}$ indicating that the copolymer behavior can substantially be influenced by the presence of molecules of different hydrophobicity in one copolymer sample. Acetone $(>99.5 \%)$ and hexane $(>99 \%)$ are from Aldrich.

All of the mixtures were prepared by mass $( \pm 0.01 \mathrm{mg})$. Water from reverse osmosis (Elga model Option 3) with a specific resistivity higher than $1 \mathrm{M} \Omega \mathrm{cm}$ was used for preparing aqueous solutions.

Volume. The densities of the aqueous mixtures were measured at $25^{\circ} \mathrm{C}$ by using a vibrating tube flow densimeter (Model 03D, Sodev Inc.) sensitive to $3 \mathrm{ppm}$. The temperature stability was within $0.001{ }^{\circ} \mathrm{C}$ by using a closed loop temperature controller (Model CT-L, Sodev Inc.).

The apparent molar volume of $\mathrm{CD}\left(\mathrm{V}_{\Phi, \mathrm{CD}}\right)$ in a given water + copolymer mixture was calculated by means of the following equation

$$
V_{\Phi, \mathrm{CD}}=\frac{\mathrm{MW}_{\mathrm{CD}}}{d}-\frac{10^{3}\left(d-d_{0}\right)}{m_{\mathrm{CD}} d d_{0}}
$$

where $m_{\mathrm{CD}}$ and $\mathrm{MW}_{\mathrm{CD}}$ are the molality and the molecular weight of the CD, respectively; $d$ and $d_{0}$ are the densities $\left(\mathrm{g} \mathrm{cm}^{-3}\right)$ of the solution and the solvent mixture, respectively. The CD concentration was kept constant $\left(m_{\mathrm{CD}}=0.175 \mathrm{~mol} \mathrm{~kg}^{-1}\right)$. The $V_{\Phi, \mathrm{CD}}$ uncertainty is $0.03 \mathrm{~cm}^{3} \mathrm{~mol}^{-1}$.

The volume of transfer of the $\mathrm{CD}$ from water to the water + copolymer mixture $\left(\Delta V_{\mathrm{t}, \mathrm{CD}}\right)$ was calculated as the difference between $V_{\Phi, C D}$ in the water + copolymer mixture and that in water calculated from the literature data. ${ }^{33}$

$\Delta V_{\mathrm{t}, \mathrm{CD}}$ values for some mixtures were measured for $48 \mathrm{~h}$ and nearly no time effect was detected (Table 2). Notwithstanding, all of the aqueous mixtures were analyzed after $24 \mathrm{~h}$ from their preparation. They were isotropic, indicating that the eventual inclusion complexes are highly soluble in water.

Surface Tension. A programmable tensiometer (KSV Sigma 70) equipped with a Wilhemy plate was used at $25.0 \pm 0.1{ }^{\circ} \mathrm{C}$. A concentrated copolymer (or CD) in the water $+\mathrm{CD}$ (or water + copolymer) solvent was added to the corresponding solvent to obtain various copolymer (or CD) compositions. Moreover, the solvent mixtures (water $+\mathrm{CD}$ and water + copolymer) were studied as functions of concentration. The surface tension of
TABLE 2: Time Dependence of Volume of Transfer of Cyclodextrins $\left(0.175 \mathrm{~mol} \mathrm{~kg}^{-1}\right)$ from Water to the Aqueous Solution of $\mathrm{F} 68\left(8 \mathrm{mmol} \mathrm{kg}{ }^{-1}\right)$ at $25^{\circ} \mathrm{C}^{a}$

\begin{tabular}{ccc}
\hline time & $\Delta \mathrm{V}_{\mathrm{t}, \mathrm{CD}}{ }^{b}$ & $\Delta \mathrm{V}_{\mathrm{t}, \mathrm{CD}}{ }^{c}$ \\
\hline 5.5 & & -1.74 \\
8.3 & 0.86 & -1.75 \\
24.0 & 0.87 & -2.01 \\
48.5 & 1.01 & -2.12 \\
${ }^{a}$ Units are as follows: time, $\mathrm{h} ; \Delta V_{\mathrm{t}, \mathrm{CD}} \mathrm{cm}^{3} \mathrm{~mol}^{-1} .{ }^{b} \mathrm{HP}-\beta-\mathrm{CD}$. \\
${ }^{c} \mathrm{HP}-\alpha-\mathrm{CD}$.
\end{tabular}

each solution was measured as a function of time to ensure that the equilibrium was reached. Each experimental point is the average value of three determinations and its precision is 0.1 dyn $\mathrm{cm}^{-1}$. The surface pressure $(\pi)$ was calculated as $\left(\gamma_{\mathrm{o}}-\gamma\right)$ where $\gamma_{0}$ and $\gamma$ are the surface tension of the solvent and the solution, respectively.

Differential Scanning Calorimetry. The measurements were performed with the TA Instruments DSC (2920 CE) under nitrogen flow atmosphere (flow rate $=60 \mathrm{~cm}^{3} \mathrm{~min}^{-1}$ ) in the -30 to $+160{ }^{\circ} \mathrm{C}$ interval with a rate of $10{ }^{\circ} \mathrm{C} \mathrm{min}^{-1}$. In the range of temperature investigated, the melting of the $\mathrm{EO}$ units is only registered..$^{34}$

The used pans were in aluminum and contained ca. $5 \mathrm{mg}$ of the sample. The calibration was carried out by using indium standard (the temperature and the enthalpy of melting are 156.51 ${ }^{\circ} \mathrm{C}$ and $28.71 \mathrm{~J} \mathrm{~g}^{-1}$, respectively). The enthalpy of melting was estimated by the endothermic peak. For a given system composed of $\mathrm{CD}$ and copolymer (or polymer), the concentration was expressed as $C_{\%}=10^{2} g_{\mathrm{P}} /\left(g_{\mathrm{P}}+g_{\mathrm{CD}}\right)$ where $g_{\mathrm{P}}$ and $g_{\mathrm{CD}}$ are the grams of copolymer (or polymer) and $\mathrm{CD}$, respectively. Some examples of thermograms are reported in the Supporting Information.

Thermogravimetry (TGA). TGA experiments were performed by using a Q500 apparatus (TA Instruments) under the nitrogen flow of $60 \mathrm{~cm}^{3} \mathrm{~min}^{-1}$ for the sample and $40 \mathrm{~cm}^{3} \mathrm{~min}^{-1}$ for the balance. A heating rate of $10{ }^{\circ} \mathrm{C} \mathrm{min}^{-1}$ was set. The temperature ranged between 150 and $600{ }^{\circ} \mathrm{C}$. The sample weight was ca. $15 \mathrm{mg}$. The temperature at which $50 \%$ of mass loss for each precursor ( $\mathrm{CD}$ and macromolecule) occurred after that the degradation started was evaluated from the temperature weight loss rate vs temperature curves. Details on the procedure are reported in the Supporting Information where some examples of TGA curves are also illustrated.

FTIR. The FTIR spectra in $\mathrm{KBr}$ pellets were measured with a Perkin-Elmer FT-IR Spectrum One instrument. The explored range was $4000-250 \mathrm{~cm}^{-1}$. The spectral resolution was $2 \mathrm{~cm}^{-1}$. Each spectrum was repeated eight times. The average values are reported.

\section{Results and Discussion}

I. Thermodynamics of ICs Formation in Water. It is very well recognized that thermodynamic properties, such as volume ${ }^{33,35-37}$ enthalpy, ${ }^{9,37-41}$ heat capacity, ${ }^{33,36,42}$ compressibility, ${ }^{43}$ etc., are excellent functions to demonstrate the formation of CD/additive inclusion complexes. The mechanism of inclusion of a guest into the CD cavity has been elucidated ${ }^{9,39,40}$ and it is mainly controlled by the following key factors: (1) the desolvation of the guest; (2) the expulsion of water molecules from the CD cavity during the inclusion process; (3) the nature of the host-guest interactions.

Literature studies ${ }^{18-20,30}$ have shown that macromolecular compounds may be included into the $\mathrm{CD}$ cavity but no thermodynamic information are available at all. On this basis, 


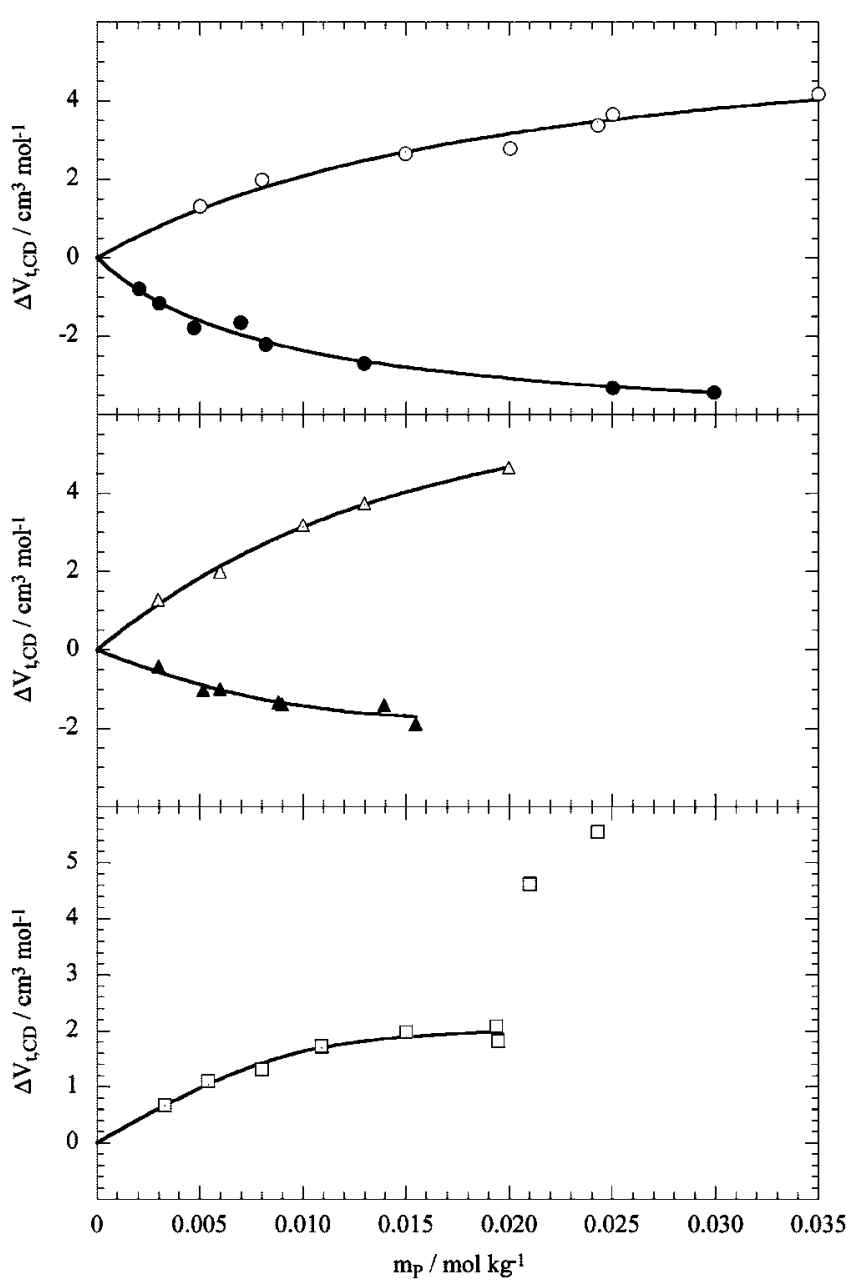

Figure 1. Volume of transfer of HP- $\alpha-\mathrm{CD}$ (filled symbols) and HP$\beta$-CD (empty symbols) from water to the aqueous F68 (circles), F88 (triangles) and L64 (squares) solutions as a function of the copolymer concentration. The lines are best fits according to eqs 3 and 5 .

TABLE 3: Thermodynamic Properties for the Copolymer + Cyclodextrin Inclusion Complex Formation at $25^{\circ} \mathrm{C}^{a}$

\begin{tabular}{lcccr}
\hline & & $K_{1}$ & $-\Delta G_{1}{ }^{\circ}$ & \multicolumn{1}{c}{$\Delta V_{1}$} \\
\hline F88 & HP- $\alpha$-CD & $600 \pm 200$ & $15.8 \pm 0.8$ & $-2.1 \pm 0.1$ \\
F88 & HP- $\beta$-CD & $110 \pm 20$ & $11.6 \pm 0.5$ & $7.5 \pm 0.3$ \\
F68 & HP- $\alpha$-CD & $110 \pm 30$ & $11.6 \pm 0.6$ & $-4.4 \pm 0.2$ \\
F68 & HP- $\beta$-CD & $58 \pm 6$ & $10.1 \pm 0.2$ & $6.1 \pm 0.3$ \\
L64 & HP- $\beta$-CD & $1100 \pm 300$ & $17.5 \pm 0.7$ & $2.16 \pm 0.05$
\end{tabular}

${ }^{a}$ Units are as follows: $K_{1}, \mathrm{~kg} \mathrm{~mol}^{-1} ; \Delta G_{1}{ }^{\mathrm{o}}, \mathrm{kJ} \mathrm{mol}^{-1} ; \Delta V_{1}, \mathrm{~cm}^{3}$ $\mathrm{mol}^{-1}$.

a volumetric investigation on aqueous Pluronics/CD mixtures was performed.

1. Results. The volumes of transfer of HP- $\alpha-C D$ and HP$\beta$-CD from water to the aqueous copolymer solutions $\left(\Delta V_{\mathrm{t}, \mathrm{CD}}\right)$ as functions of the copolymer molality $\left(m_{\mathrm{P}}\right)$ are illustrated in Figure 1. Unfortunately, the F88 + CD + water mixtures were viscous and only a restricted range of $m_{\mathrm{P}}$ was investigated.

The $\Delta V_{\mathrm{t}, \mathrm{CD}}$ vs $m_{\mathrm{P}}$ trends are monotonic while the sign of the $\Delta V_{\mathrm{t}, \mathrm{CD}}$ values is specific of the $\mathrm{CD}$ nature being negative for HP- $\alpha-C D$ and positive for HP- $\beta$-CD. This result is not unusual because the inclusion of small sized solutes into the $\alpha-C D$ or HP- $\alpha-C D$ generates negative volume ${ }^{9,35}$ and enthalpy ${ }^{9}$ and opposite values $^{33,40}$ in $\beta$-CD or HP- $\beta$-CD. The $\Delta V_{\mathrm{t}, \mathrm{CD}}$ vs $m_{\mathrm{P}}$
TABLE 4: Stoichiometry of the Copolymer + Cyclodextrin Inclusion Complexes Obtained from DSC and Volumetric Experiments $^{a}$

\begin{tabular}{llllll}
\hline & \multicolumn{1}{c}{ F108 } & \multicolumn{1}{c}{ F88 } & F68 & L64 & F127 \\
\hline HP- $\alpha$-CD & $0.042^{b}$ & $0.056 ;^{b} 0.049^{c}$ & $0.066^{b}$ & & $0.042^{b}$ \\
HP- $\beta$-CD & $0.040 ;^{b} 0.045^{d}$ & $0.048^{c}$ & & $0.053^{c}$ & \\
HP- $\gamma$-CD & $0.069^{b}$ & & & & \\
$\alpha$-CD & $0.0062^{b}$ & & & & \\
$\beta$-CD & $0.0091^{b}$ & & & &
\end{tabular}

${ }^{a}$ Unit: mol of copolymer/mol of cyclodextrin. ${ }^{b}$ From DSC data. ${ }^{c}$ From volume data. ${ }^{d}$ The residual dried matter was obtained evaporating water under vacuum at $25^{\circ} \mathrm{C}$.

trend for L64 + HP- $\beta$-CD shows two-steps; the break at ca. $0.02 \mathrm{~mol} \mathrm{~kg}^{-1}$ may be ascribed to the L64 aggregation. ${ }^{23} \mathrm{~A}$ further analysis of the plots in Figure 1 highlights that the $\Delta V_{\mathrm{t}, \mathrm{CD}}$ values increase in magnitude with the copolymer molecular weight $\left(M W_{\mathrm{p}}\right)$ and the copolymer hydrophilicity.

2. Quantitative Analysis. The monotonic change of the volumes of transfer with $m_{\mathrm{P}}$ may be interpreted in terms of the copolymer encapsulation into the CD cavity. The used approach for modeling the bulk properties assumes that the copolymer is composed of a certain number of sites of binding each one interacting with one $\mathrm{CD}$ molecule according to the following equation

$$
S_{\mathrm{t}}=z m_{\mathrm{P}}
$$

where $S_{\mathrm{t}}$ is the total number of interaction sites per $\mathrm{kg}$ of water and $z$ is the number of moles of sites contained in $1 \mathrm{~mol}$ of the copolymer. This model is an exemplification of a more complex approach proposed ${ }^{44}$ for determining the thermodynamics of formation of single and double layers of polymers on the solid substrates. The following equation can be written

$$
\Delta V_{\mathrm{t}, \mathrm{CD}}=x_{1} \Delta V_{1}
$$

where $x_{1}$ is the fraction of the $\mathrm{CD}$ involved in the one-to-one binding whereas $\Delta V_{1}$ is the corresponding volume change per mole of CD.

The equilibrium constant $\left(K_{1}\right)$ and the copolymer mass balance are given by

$$
K_{1}=x_{1} /\left[m_{\mathrm{P}, \mathrm{w}}\left(1-x_{1}\right)\right] \quad m_{\mathrm{P}}=m_{\mathrm{P}, \mathrm{w}}+x_{1} m_{\mathrm{CD}} / z
$$

where $m_{\mathrm{P}}$ and $m_{\mathrm{CD}}$ are the stoichiometric copolymer and CD molalities, respectively, whereas $\mathrm{m}_{\mathrm{P}, \mathrm{w}}$ is the copolymer molality in the aqueous phase. By combining $K_{1}$ and the copolymer mass balance, one obtains

$$
\begin{aligned}
x_{1}= & \left\{K_{1} m_{\mathrm{CD}} / z+K_{1} m_{\mathrm{p}}+1-\left[\left(K_{1} m_{\mathrm{CD}} / z\right)^{2}+\right.\right. \\
& \left.\left.2 K_{1} m_{\mathrm{CD}}\left(1-K_{1} m_{\mathrm{P}}\right) / z+\left(K_{1} m_{\mathrm{P}}\right)^{2}+2 K_{1} m_{\mathrm{P}}+1\right]^{0.5}\right\} / \\
& \quad\left(2 K_{1} m_{\mathrm{CD}} / z\right)
\end{aligned}
$$

Introducing eq 5 into eq 3 , one obtains an equation with three unknown parameters $\left(K_{1}, z\right.$, and $\left.\Delta V_{1}\right)$, which are determined by using a nonlinear least-squares fitting method. The best fits are shown in Figure 1 . The $\Delta V_{1}, K_{1}$ and the standard free energy $\left(\Delta G_{1}{ }^{\circ}=-R T \ln K_{1}\right)$ are reported in Table 3 . In the case of $\mathrm{F} 68$, the $z$ values were not detectable because the amount of the copolymer included into the $\mathrm{CD}$ was negligible compared to $m_{\mathrm{P}}$. Note that $1 / z$ corresponds to the stoichiometry expressed as the ratio between the moles of copolymer and $\mathrm{CD}\left(n_{\mathrm{P}} / n_{\mathrm{CD}}\right)$; it is reported in Table 4.

3. Discussion. We first describe the behavior of F68 and F88 in the presence of HP- $\alpha-\mathrm{CD}$. The order $\Delta G_{1}{ }^{\circ}(\mathrm{F} 88)<\Delta G_{1}{ }^{\circ}(\mathrm{F} 68)$ 


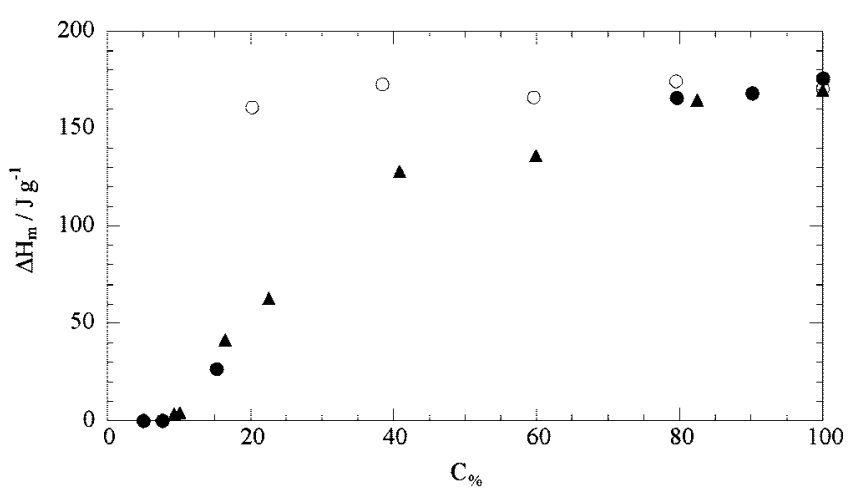

Figure 2. Enthalpy of melting per gram of PEG as a function of the polymer weight percent of the aqueous mixtures of PEG $900 / \alpha-C D$

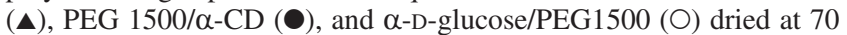
${ }^{\circ} \mathrm{C}$ at ambient pressure.

shows that the lengthening of the PEO block favors the threading of the copolymer. The negative $\Delta V_{1}$ reveals the predominance of the van der Waals interaction and the displacement of a reduced number of water molecules from the HP- $\alpha-C D$ cavity. Accordingly, semiquantitative calculations ${ }^{35}$ showed that the negative volume for the $\alpha-\mathrm{CD} /$ alkanoate inclusion complexes formation, opposite in the sign to the corresponding ones for $\beta$-CD/alkanoate, derives from the release of fewer water molecules from $\alpha$-CD. Moreover, $\Delta V_{1}(\mathrm{~F} 88)$ is larger than $\Delta V_{1}(\mathrm{~F} 68)$, which can be explained by invoking the more important positive ${ }^{45}$ contribution of the desolvation of F88. The increasing copolymer size also stabilizes the ICs composed of HP- $\beta$-CD (Table 3 ).

The copolymer hydrophobicity enhances the inclusion power of $\mathrm{HP}-\beta$-CD demonstrating that the hydrophobic desolvation is an important key in the ICs formation. The order $\Delta V_{1}(\mathrm{~F} 68)>$ $\Delta V_{1}$ (L64) likely reveals the larger desolvation of the EO segments which undergo the encapsulation into the CD cavity as both copolymers have the same PPO block. Finally, the binding forces between HP- $\beta$-CD and a given copolymer are relatively weak because the wide $\mathrm{CD}$ cavity does not fit well the copolymer.

II. DSC for Determining the ICs Stoichiometry. It is wellknown that $\mathrm{NMR}^{1,5,30}$ is the most used technique for determining the polymer/CD inclusion complex stoichiometry. Recently, TGA experiments ${ }^{15}$ provided acceptable values of such a stoichiometry, which was not as accurate as that from NMR. The DSC is potentially an useful technique to describe the behavior of ICs in the solid state and to determine the stoichiometry with a good accuracy. With this in mind, PEG 900/ $\alpha-C D$ and PEG $1500 / \alpha-C D$ were selected because the inclusion of PEG in $\alpha-C D$ is well documented ${ }^{1,5}$ and the stoichiometry of 2 EO units per mole of $\alpha-C D$ is accepted. Experimentally, pure PEG and $\alpha-C D$ were added to water and equilibrated for $48 \mathrm{~h}$. Thereafter, the mixtures were kept at 70 ${ }^{\circ} \mathrm{C}$ for 2 days and the residual dried matter (RDM) was analyzed by means of DSC technique.

Figure 2 shows the enthalpy of melting $\left(\Delta H_{\mathrm{m}}\right)$ vs the PEG mass percent $\left(C_{\%}\right)$. The $\Delta H_{\mathrm{m}}$ values define a sigmoidal profile that shows a null $\Delta H_{\mathrm{m}}$ value up to a given $C_{\%}$ after which it increases monotonically reaching the value of the enthalpy of melting of the pure polymer $\left(\Delta H_{\mathrm{m}} *\right)$. According to the literature, ${ }^{16,30}$ the order $\Delta H_{\mathrm{m}}<\Delta H_{\mathrm{m}} *$ reflects the reduced amount of the EO segments in the crystalline state due to the inclusion of the polymer into $\alpha$-CD. The null $\Delta H_{\mathrm{m}}$ values indicate that all of the polymer lost the crystallinity. When $\Delta H_{\mathrm{m}}$ starts to deviate from zero (break in the curve), all of the CD is

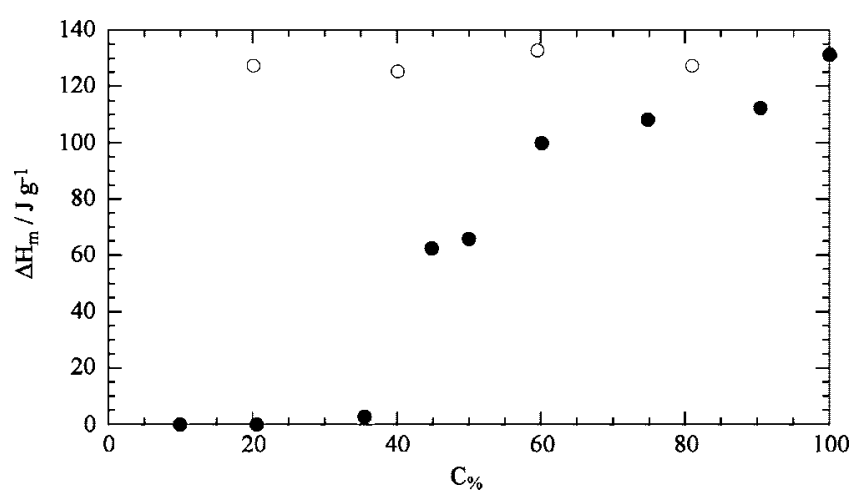

Figure 3. Enthalpy of melting per gram of F88 as a function of the copolymer weight percent of the aqueous mixtures of F88/HP- $\alpha-C D$ (๑) and $\alpha$-D-glucose/HP- $\alpha$-CD (O) dried at $70{ }^{\circ} \mathrm{C}$ at ambient pressure.

in the complexed state and the further added polymer contributes to $\Delta H_{\mathrm{m}}$ being that it is in the free state. Indeed, $\Delta H_{\mathrm{m}}$ could also reveal some no-specific interactions generating an amorphous mixture. To evidence such an effect, DSC measurements were carried out on the RDM from water $+\alpha$-D-glucose + PEG1500 where the $\alpha$-D-glucose, being the monomer of the $\mathrm{CD}$, well mimes the external CD surface. The independence of $\Delta H_{\mathrm{m}}$ on $C_{\%}$ (Figure 2) confirms our interpretation of the sigmoidal $\Delta H_{\mathrm{m}}$ trend the break point of which is ascribable to the IC stoichiometry. For a straightforward evaluation, the latter was calculated as intersection point between the two straight lines obtained by plotting $\Delta H_{\mathrm{m}}$ vs $1 / C_{\%}$ (see Supporting Information). The stoichiometry values obtained for both PEG $900 / \alpha-C D$ and PEG 1500/ $\alpha$-CD (2.1 EO units per mole of $\alpha$-CD) agrees with that reported ${ }^{1,5}$ for PEG1000/ $\alpha$-CD (2.0 EO units per mole of $\alpha-C D)$.

The DSC method was further validated by studying the HP$\alpha-\mathrm{CD}+\mathrm{F} 88$ system. Figure 3 shows a sigmoidal $\Delta H_{\mathrm{m}}$ vs $C_{\%}$ curve which provides an IC stoichiometry of $11 \mathrm{~mol}$ of EO units per mol of HP- $\alpha-C D$. Two independent methods corroborated our approach. First, $\Delta H_{\mathrm{m}}$ on $\alpha$-D-glucose + F88 ruled out the presence of no-specific interactions (Figure 3). Second, the experimental $\Delta H_{\mathrm{m}}$ vs $C_{\%}$ trend for HP- $\alpha-\mathrm{CD}+\mathrm{F} 88$ was quantitatively simulated (Figure 4) by using the $K_{1}$ and $z$ values (derived from the earlier volumetric studies) and $\Delta H_{\mathrm{m}}{ }^{*}$ based on the following points: (1) $\Delta H_{\mathrm{m}}=x_{\mathrm{P}, \mathrm{f}} \Delta H_{\mathrm{m}} *$ where $x_{\mathrm{P}, \mathrm{f}}$ is the fraction of free copolymer; (2) $x_{\mathrm{P}, \mathrm{f}}$ is calculated by using the $K_{1}$ and $z$ values; (3) $x_{\mathrm{P}, \mathrm{f}}$ has to be computed under the conditions of the DSC experiments, i.e., when the solvent of the mixture is nearly absent. Figure 4 shows the dependence of $x_{\mathrm{P}, \mathrm{f}}$ on the ratio between the initial $\left(V_{\mathrm{i}}\right)$ and the final $\left(V_{\mathrm{f}}\right)$ volumes of two $\mathrm{F} 88+\mathrm{HP}-\alpha-\mathrm{CD}$ mixtures. Evaporating the solvent shifts the equilibrium toward the IC formation. In fact, $\mathrm{x}_{\mathrm{P}, \mathrm{f}}$ decreases with $V_{\mathrm{i}} / V_{\mathrm{f}}$ and reaches a constant value for $V_{\mathrm{i}} / V_{\mathrm{f}}>100$; mixture with low $\mathrm{C} \%$ value, $x_{\mathrm{P}, \mathrm{f}}$ achieves a null value. The $\Delta H_{\mathrm{m}}$ values were calculated at different $V_{\mathrm{i}} / V_{\mathrm{f}}$ ratios and plotted in Figure 4 together with the experimental points. It is striking to observe that by increasing the $V_{\mathrm{i}} / V_{\mathrm{f}}$ ratio the computed $\Delta H_{\mathrm{m}}$ values become closer and closer to the experimental data, and for $V_{\mathrm{i}} /$ $V_{\mathrm{f}}>100$, they do not change anymore and fit quantitatively the experimental data.

All of the above arguments finally confirm the validation of the DSC method used to quantitatively study the ICs.

III. Solvent Nature on the ICs Formation. The solvent nature on the ICs formation was explored by using water, acetone and hexane very different in the polarity. Pure F108 and HP- $\alpha-C D$ were added to a given solvent and equilibrated 


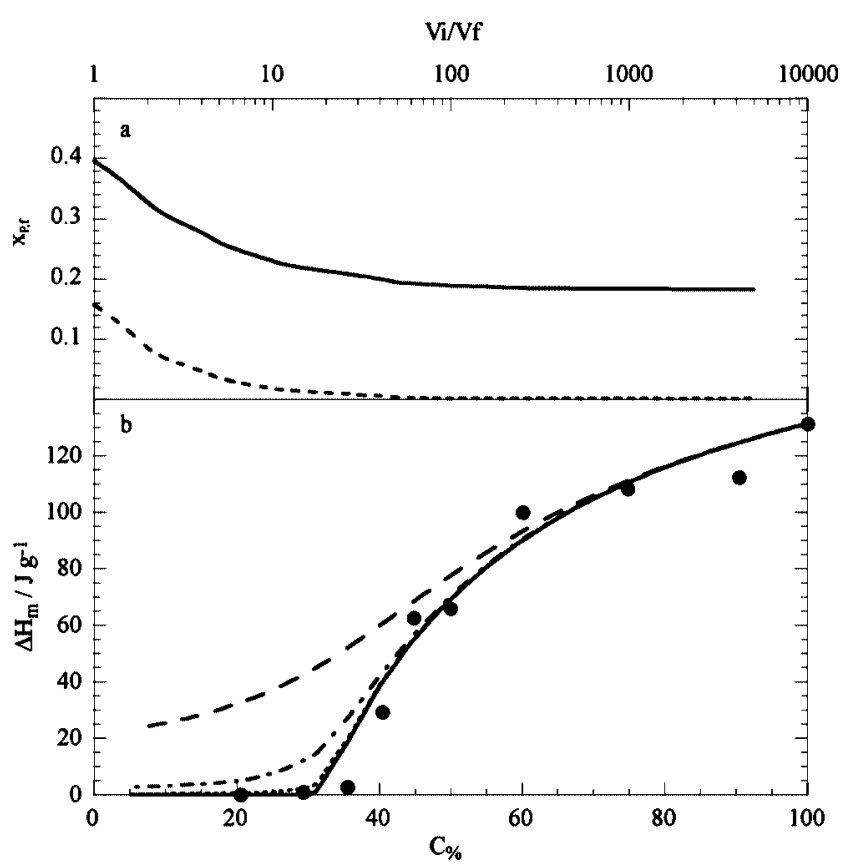

Figure 4. (a) Dependence of the fraction of free copolymer on the ratio between the initial and the final volume of the aqueous HP- $\alpha-$ CD+F88 mixtures: $(--) C_{\%}=5 ;(-) C_{\%}=40$. (b) Experimental $(\bullet)$ and simulated (lines) enthalpies of melting at various $V_{\mathrm{i}} / V_{\mathrm{f}}$ ratios: $(--)$ $1,(-\cdot-) 10,(\cdots) 100$, and $(-) 5000$.

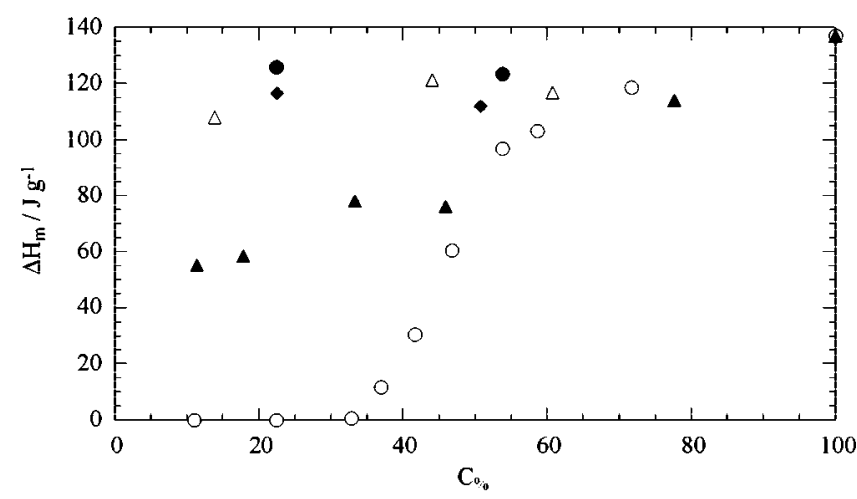

Figure 5. Enthalpy of melting per gram of F108 as a function of the copolymer weight percent for the F108/HP- $\alpha-C D$ system: F108 and $\mathrm{HP}-\alpha-\mathrm{CD}$ physically mixed at $70{ }^{\circ} \mathrm{C}(\mathbf{)})$; F108 and HP- $\alpha-\mathrm{CD}$ added to water $(O)$, hexane $(\Delta)$, and acetone $(\mathbf{\Delta})$ and dried at $70{ }^{\circ} \mathrm{C}$ at ambient pressure. F108 and HP- $\gamma$-CD physically mixed at $70{ }^{\circ} \mathrm{C}(\boldsymbol{})$.

for $48 \mathrm{~h}$. The mixtures with acetone and hexane were dispersions while those with water were isotropic solutions. The RDM (obtained as described above) was analyzed by means of DSC technique. The $\Delta H_{\mathrm{m}}$ values of the various systems as functions of $C_{\%}$ are illustrated in Figure 5. Specifically, the RDM from hexane and acetone provided $\Delta H_{\mathrm{m}}$ values which are constant and increasing functions of composition, respectively. The $\Delta H_{\mathrm{m}}$ values of RDM from water define a sigmoidal profile which evidence the presence of ICs. In some cases, pure CD and copolymer (namely, F108 + HP- $\alpha-C D$ and F108 + HP- $\gamma$-CD) were physically mixed and stirred for 2 days at $70{ }^{\circ} \mathrm{C}$. The determined $\Delta H_{\mathrm{m}}$ are nearly equal to $\Delta H_{\mathrm{m}}{ }^{*}$. Same behavior was exhibited by the system composed of F68 and HP- $\alpha-\mathrm{CD}\left(C_{\%}\right.$ $=29.5)$ as after 24 and $94 \mathrm{~h}$ from their combination, the $\Delta H_{\mathrm{m}}$ values (133 and $129 \mathrm{~J} \mathrm{~g}^{-1}$, respectively) were equal to $\Delta H_{\mathrm{m}}{ }^{*}$ $\left(132.5 \mathrm{~J} \mathrm{~g}^{-1}\right) .{ }^{34}$

In conclusion, one may infer that within the window-time of investigation: (1) the goodness of the solvent follows the order

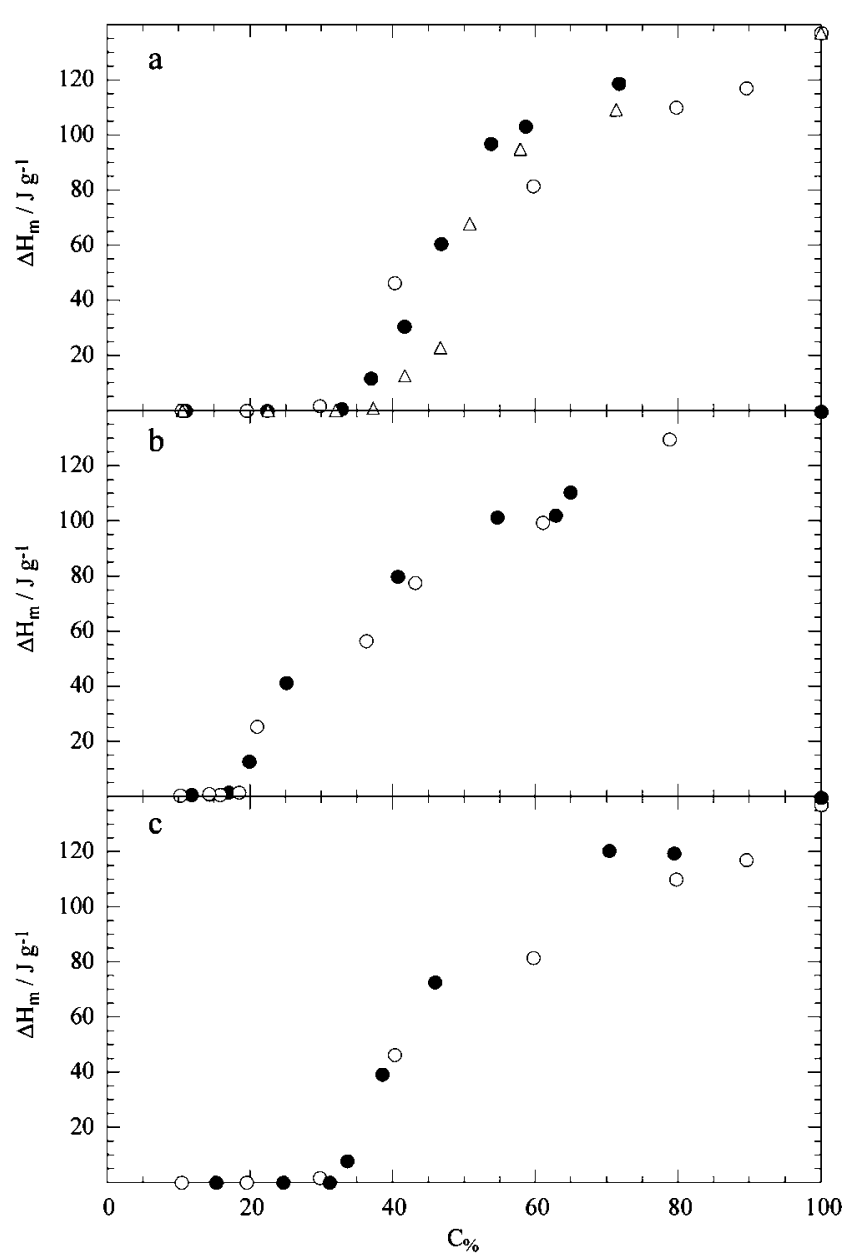

Figure 6. Enthalpy of melting per gram of F108 as a function of the copolymer weight percent for the mixtures F108/cyclodextrin prepared in water and dried at $70{ }^{\circ} \mathrm{C}$ at ambient pressure: (a) $\mathrm{HP}-\alpha-\mathrm{CD}(\bullet)$, HP- $\beta$-CD (O), and HP- $\gamma$-CD ( $\Delta$ ); (b) $\alpha$-CD (๑) and $\beta$-CD (O); (c) aqueous HP- $\beta-\mathrm{CD} / \mathrm{F} 108$ mixtures dried at $25{ }^{\circ} \mathrm{C}$ under vacuum $(\bullet)$ and dried at $70{ }^{\circ} \mathrm{C}$ at ambient pressure $(\mathrm{O})$.

hexane $<$ acetone $<$ water and (2) the physical mixing of $\mathrm{CD}$ and copolymer does not lead to the ICs formation. Consequently, hereafter water will be used as solvent.

IV. Effect of the Cyclodextrin Nature on ICs. Insights on the effect of the alkylation of the CD on the inclusion of F108 were drawn by comparing $\alpha-\mathrm{CD}$ and $\beta$-CD to the corresponding HP- $\alpha-C D$ and HP- $\beta$-CD, respectively (Figures $6 \mathrm{a}$ and $6 \mathrm{~b}$ ). The $\mathrm{CD}$ alkylation does not affect the profile of the $\Delta H_{\mathrm{m}}$ vs $C_{\%}$ curve while it does the onset of the enthalpy which occurs at larger compositions for the alkylated CDs. By remembering that $\Delta H_{\mathrm{m}}$ is selective to the melting of the EO units, one may conclude that all of these data straightforwardly prove that the CD cavity includes EO units of F108, in some extent, whatever is its nature. The ICs stoichiometries (Table 4) for hydroxypropyl-CDs are ca. 1 order of magnitude larger than those of the native CDs. To the light of findings for similar systems, ${ }^{18,19}$ these results were unexpected for $\beta-\mathrm{CD}$ and $\mathrm{HP}-\beta-\mathrm{CD}$ which are believed to include the PO units. Harada et al. ${ }^{1,2}$ report that $\beta$-CD does not incorporate PEG because of the large cavity of the CD. NMR studies ${ }^{46}$ evidenced weak interactions between PEG and methylated $\beta$-CDs ascribed not only to the size of the guest but also to the hydrophobic forces. On the contrary, PPO forms inclusion complexes with 2,6- $O$-dimethyl- $\beta$-cyclodextrin (DM- $\beta$-CD). ${ }^{46}$ Specific forces between the PPO block of Pluronics and DM- $\beta$-CD were highlighted through static light scattering ${ }^{18}$ and small angle neutron scattering studies. ${ }^{20}$ To the 
TABLE 5: Moles of EO Included in the Copolymer + Cyclodextrin Complex per Mole of $\mathrm{CD}^{a}$

\begin{tabular}{lcc}
\hline cyclodextrin & copolymer & stoichiometry $^{b}$ \\
\hline$\beta-\mathrm{CD}$ & $\mathrm{F} 108$ & 2.4 \\
$\alpha-\mathrm{CD}$ & $\mathrm{F} 108$ & 1.6 \\
HP- $\gamma$-CD & $\mathrm{F} 108$ & 18 \\
HP- $\beta$-CD & $\mathrm{F} 108$ & 11 \\
HP- $\alpha-\mathrm{CD}$ & $\mathrm{F} 108$ & 11 \\
HP- $\alpha-\mathrm{CD}$ & $\mathrm{F} 88$ & 11 \\
HP- $\alpha-\mathrm{CD}$ & $\mathrm{F} 68$ & 10 \\
HP- $\alpha-\mathrm{CD}$ & $\mathrm{F} 127$ & 8
\end{tabular}

${ }^{a}$ From DSC. ${ }^{b}$ Moles of EO units per moles of cyclodextrin. The uncertainty is $\approx 10 \%$.

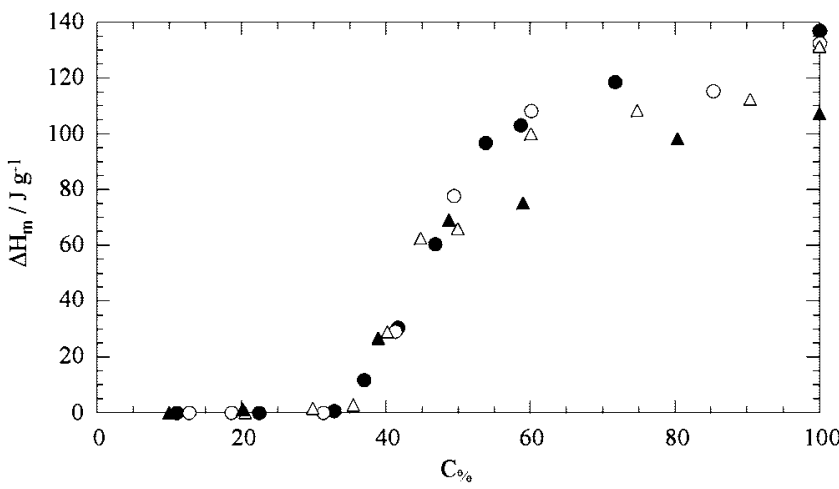

Figure 7. Enthalpy of melting per gram of copolymer as a function of the copolymer weight percent for the aqueous mixtures composed

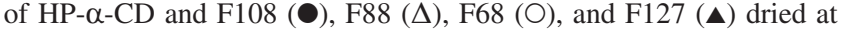
$70{ }^{\circ} \mathrm{C}$ at ambient pressure.

best of our knowledge, very few ${ }^{47,48}$ are the evidence for the attractive forces between PEO and $\beta$-CD. Fujita et al. ${ }^{47}$ reported that for polyrotaxanes consisting of $\beta-\mathrm{CD}$ and Pluronics the majority of $\beta$-CD interacts with the PPO segments but some $\mathrm{CD}$ molecules reside on the PEO blocks. Moreover, a mixture of PEO and $\beta$-CD in the presence of small amounts of water heated for several months produced single crystals of inclusion complexes. ${ }^{48}$

The impact of the CD cavity size on the formation of ICs was explored by studying F108 in HP- $\alpha-C D, H P-\beta-C D$, and HP- $\gamma$-CD. A careful inspection of the experimental data shown in Figure 6a highlights that the points in the presence of HP$\alpha-\mathrm{CD}$ and HP- $\beta$-CD show the break at the same $C_{\%}$ value whereas those for HP- $\gamma$-CD do so at a larger composition (ca. $40 \% \mathrm{w} / \mathrm{w})$. The situation remains unchanged when $\alpha-C D$ and $\beta$-CD are compared (Figure $6 \mathrm{~b}$ ). The $n_{\mathrm{EO}} / n_{\mathrm{CD}}$ ratio value (Table 5) for $\mathrm{HP}-\gamma-\mathrm{CD} / \mathrm{F} 108$ mixture is about twice that for HP- $\alpha-\mathrm{CD}$ and $\mathrm{HP}-\beta-\mathrm{CD}$. According to the literature report ${ }^{7,49}$ on IC formed by $\gamma$-CD and modified PEG, a doubled-stranded IC is likely formed.

To highlight the temperature effect, additional experiments on the RDM of the aqueous F108/HP- $\beta$-CD mixtures were performed. Namely, the aqueous solvent was evaporated at 25 ${ }^{\circ} \mathrm{C}$ with the help of a vacuum pump. Figure $6 \mathrm{c}$ shows that the stoichiometry of the ICs is nearly temperature independent (Table 4).

V. Effect of the Copolymer Nature on ICs. The variation of the copolymer size was studied by analyzing F68, F88, and F108 (all having the same EO/PO ratio) in the presence of HP$\alpha$-CD. The $\Delta H_{\mathrm{m}}$ vs $C_{\%}$ trends (Figure 7 ) are $\mathrm{S}$-shaped curves as those of the other mixtures. A single sigmoidal curve can be basically drawn through all of the experimental points of the three copolymers revealing that the stoichiometry of the IC is

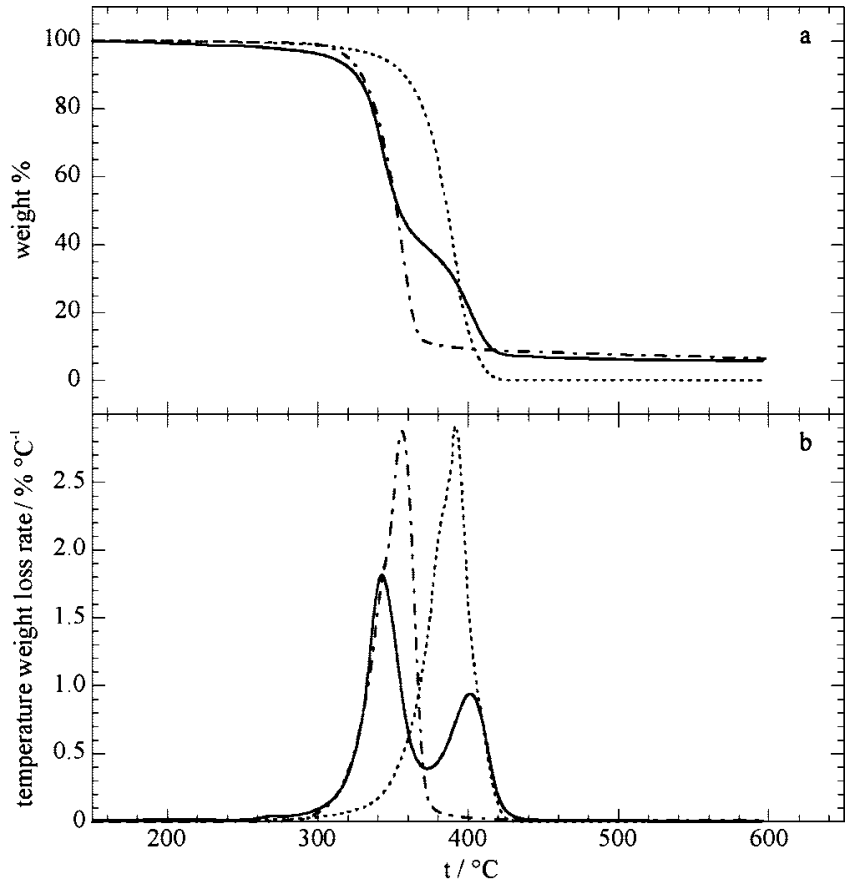

Figure 8. TGA thermograms (a) and thermal degradation rates (b) for HP- $\alpha-\mathrm{CD}(---), \mathrm{F} 88(--)$, and HP- $\alpha-\mathrm{CD}+\mathrm{F} 88$ inclusion complexs (一).

substantially established by the $\mathrm{CD}$ characteristics $\left(n_{\mathrm{EO}} / n_{\mathrm{CD}}\right.$ ratio in Table 5). From these results, one may reasonably predict the stoichiometry of the ICs formed by HP- $\alpha-C D$ and copolymers, with the EO/PO ratio of 4.0, not yet investigated. This finding assumes a particular relevance because, within this issue, a difficult task is predicting whether a polymer forms or not an inclusion complex. ${ }^{5}$

Comparing the $\Delta H_{\mathrm{m}}$ data of F88 and F127 in HP- $\alpha-C D$ emerges that the stoichiometry is very slightly influenced by the length of the PPO block size (Figure 7) reflecting the HP$\alpha-C D$ selectivity to the PEO blocks. This agrees with literature data $^{30}$ on $\alpha-C D /$ copolymer ICs and, furthermore, validates our DSC approach.

VI. Thermal Stability of ICs. According to the literature, ${ }^{12,15,16,50,51}$ the thermal stability of the ICs was controlled by TGA experiments. To this aim, we prepared the ICs samples as RDM of aqueous copolymer $+\mathrm{CD}$ mixtures with $n_{\mathrm{P}} / n_{\mathrm{CD}}$ values corresponding to the ICs stoichiometry provided by DSC (Table 4). As Figure 8a shows, the TGA thermogram of each precursor exhibits a degradation peak while that of the IC exhibits a two-steps weight loss behavior. Accordingly, the temperature weight loss rate as a function of temperature trends (Figure $8 \mathrm{~b}$ ) exhibit one peak for each pure component and two peaks for the IC. On the basis of the $\mathrm{CD} /$ copolymer moles ratio, the peaks appearing at lower and higher temperatures are assigned to the $\mathrm{CD}$ and copolymer decompositions, respectively. The temperature at which the degradation process starts is the onset of the TGA curve and may be straightforwardly evaluated for an one-step process. In our case, a two-step process occurs for the ICs (Figure 8) so that to have meaningful information we determined the degradation temperature $\left(T_{\mathrm{CD}}\right.$ and $\left.T_{\mathrm{P}}\right)$ at which $50 \%$ of mass loss for each component (CD and copolymer) takes place. The data are in Table 6 .

We first analyze the two precursors. The $T_{\mathrm{CD}}$ values of $\alpha-\mathrm{CD}$ and $\beta$-CD are close as well as those of the HP-CDs. The $T_{\mathrm{CD}}$ values of native CDs are smaller than those of the corresponding alkylated CDs revealing that the hydroxypropyl groups enhance 
TABLE 6: Decomposition Temperature ${ }^{b}$ of Cyclodextrins and Copolymers in both the Free and Complexed States Obtained from TGA Data ${ }^{a}$

\begin{tabular}{|c|c|c|c|c|c|}
\hline cyclodextrin & copolymer & $T_{\mathrm{CD}}$ & $T_{\mathrm{P}}$ & $T_{\mathrm{CD}, \mathrm{i}}-T_{\mathrm{CD}}$ & $T_{\mathrm{P}, \mathrm{i}}-T_{\mathrm{P}}$ \\
\hline$\alpha-C D$ & & 323.7 & & & \\
\hline$\beta$-CD & & 329.4 & & & \\
\hline HP- $\alpha-C D$ & & 351.0 & & & \\
\hline $\mathrm{HP}-\beta-\mathrm{CD}$ & & 346.7 & & & \\
\hline \multirow[t]{5}{*}{$\mathrm{HP}-\gamma-\mathrm{CD}$} & & 342.8 & & & \\
\hline & F68 & & 390.4 & & \\
\hline & F88 & & 386.5 & & \\
\hline & F108 & & 386.7 & & \\
\hline & F127 & & 387.6 & & \\
\hline$\alpha-C D$ & F108 & & & 6.7 & 4.4 \\
\hline$\beta-\mathrm{CD}$ & F108 & & & 5.0 & 10.9 \\
\hline $\mathrm{HP}-\alpha-\mathrm{CD}$ & F108 & & & -10.3 & 11.8 \\
\hline $\mathrm{HP}-\beta-\mathrm{CD}$ & F108 & & & -9.6 & 12.3 \\
\hline $\mathrm{HP}-\gamma-\mathrm{CD}$ & F108 & & & -12.4 & 10.8 \\
\hline $\mathrm{HP}-\alpha-\mathrm{CD}$ & F88 & & & -8.2 & 15.8 \\
\hline $\mathrm{HP}-\alpha-\mathrm{CD}$ & F68 & & & -16.9 & 8.0 \\
\hline HP- $\alpha-C D$ & F127 & & & -7.0 & 12.2 \\
\hline
\end{tabular}

${ }^{a}$ Unit for temperature is ${ }^{\circ} \mathrm{C} .{ }^{b}$ Temperature at which $50 \%$ of mass loss occurred for each precursor after the start of degradation.

the thermal stability of the macrocycle. As concerns the pure copolymers, $T_{\mathrm{P}}$ values do not essentially depend on $M W_{\mathrm{p}}$ as well as the size of the PPO block according to the $T_{\mathrm{P}}$ values of F88 and F127. Comparing data of pure precursors one deduces that the copolymers are more thermally stable than the CDs.

The native CDs which include F108 decompose at temperature $\left(T_{\mathrm{CD}, \mathrm{i}}\right)$ values slightly larger than those of pure CDs while for the alkylated CDs $T_{\mathrm{CD}, \mathrm{i}}$ are reduced by ca. $10{ }^{\circ} \mathrm{C}$ (Table 6). To our knowledge, few are the systems where the CD thermal stability decreases in the presence of the guest and it occurs for $\mathrm{FeBr}_{3}+$ native $\mathrm{CDs}(\alpha-\mathrm{CD}, \beta-\mathrm{CD} \text {, and } \gamma-\mathrm{CD})^{51}$ and $\beta-\mathrm{CD}+$ polyactide. ${ }^{52}$

The cavity size of the alkylated CDs substantially does not influence the thermal behavior of the included F108 while the cavity size of the native CDs does as the largest macrocycle enhances such a stability. The improvement of the thermal stability of the ICs by the guest has been generally observed for PCL-PTHF-PCL ${ }^{15}$ and PCL-PEO-PCL ${ }^{16}$ copolymers, conventional surfactants, ${ }^{50}$ and adamantane-modified benzoxazines. ${ }^{53}$

VII. FTIR Spectroscopy on Solid ICs. The FTIR spectra of HP- $\alpha-C D, \alpha-C D$, and F108 and their ICs in the region from 250 to $4000 \mathrm{~cm}^{-1}$ are illustrated in Figure 9 . According to the literature, ${ }^{54}$ the bands (in the spectrum of pure $\alpha-C D$ ) at 1030 and $1077 \mathrm{~cm}^{-1}$ are attributed to the coupling $\mathrm{C}-\mathrm{C} / \mathrm{C}-\mathrm{O}$ stretching vibration and the band at $1157 \mathrm{~cm}^{-1}$ to the antysimmetric stretching vibration of the $\mathrm{C}-\mathrm{O}-\mathrm{C}$ glycosidic bridge. The corresponding bands for HP- $\alpha-C D$ are located at the same frequencies. Generally, the peak in the $3000-4000 \mathrm{~cm}^{-1}$ domain is due to the symmetric and antisymmetric $\mathrm{OH}$ stretching modes. The pure $\alpha-C D$ exhibits this band at $3365 \mathrm{~cm}^{-1}$ while HP- $\alpha-$ $\mathrm{CD}$ does so at $3384 \mathrm{~cm}^{-1}$. When the $\mathrm{CD}$ encapsulates the copolymer, only the peak in the $3000-4000 \mathrm{~cm}^{-1}$ range changes its position in agreement with literature findings $; 2,54$ in particular, it appears at 3379 and $3386 \mathrm{~cm}^{-1}$ for $\alpha-C D$ and HP$\alpha-C D$, respectively. These results may reflect the capability ${ }^{5}$ of the native $\mathrm{CD}$ s to form hydrogen bonding between adjacent $\mathrm{CD}$ rings which are believed to stabilize the columnar stacking. This phenomenon does not occur for HP- $\alpha-C D$ and, therefore, the peak at $3384 \mathrm{~cm}^{-1}$ does not essentially change position.

The FTIR spectrum of pure F108 evidenced peaks already identified for other Pluronics. ${ }^{31,55}$ It is interesting to address

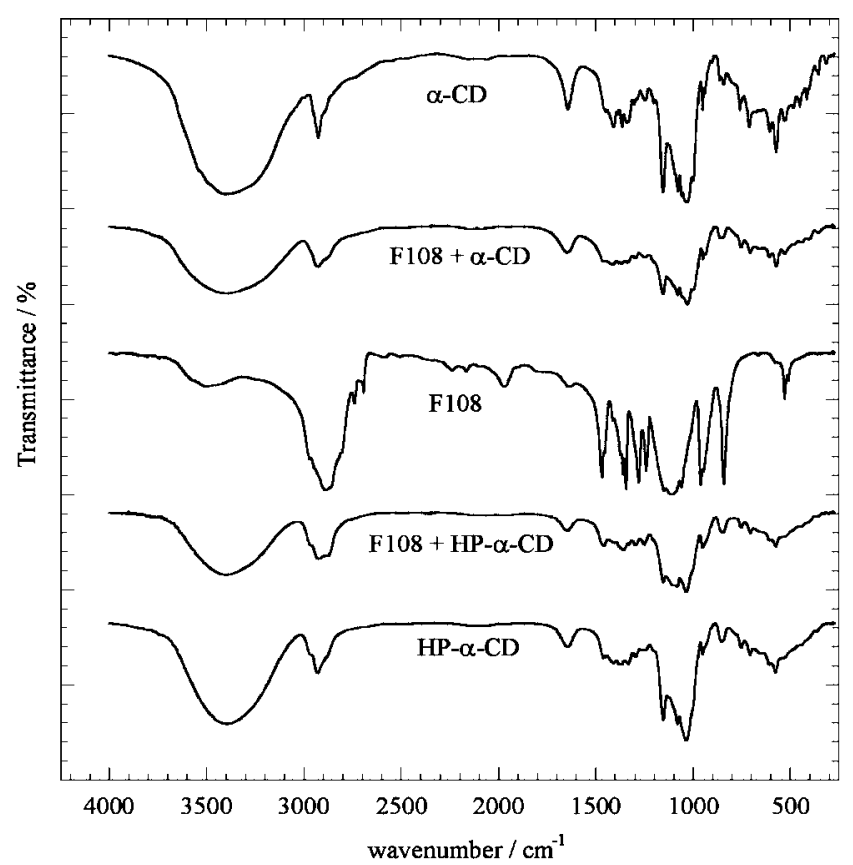

Figure 9. FTIR spectra of F108, cyclodextrins, and F108 + cyclodextrin inclusion complexes.

attention to the bands at 1242 and 1343 relative to the $\mathrm{CH}_{2}$ twist and the $\mathrm{CH}_{2}$ wag, respectively, which are typical of the crystalline state of the copolymer; they appear at 1250 and 1348 $\mathrm{cm}^{-1}$, respectively, when F108 is included into HP- $\alpha-C D$. It is striking that the bands shift from 1343 to $1348 \mathrm{~cm}^{-1}$ and from 1242 to $1250 \mathrm{~cm}^{-1}$ was ascribed ${ }^{31}$ to the crystalline-amorphous phase transition of $\mathrm{EO}_{27} \mathrm{PO}_{61} \mathrm{EO}_{27}$. Therefore, it is straightforward that the conformational state of the EO units of F108 changes from an ordered helical structure to a disordered structure when it is transferring to the HP- $\alpha-C D$ cavity corroborating the previous DSC results. It has to be noted that the copolymer looses completely the crystallinity even if it is fitted by few CD molecules. The several bands present at the same frequencies in the spectra of pure $\alpha-C D$ and F108 did not allow to obtain specific information on the copolymer included into $\alpha-\mathrm{CD}$ as done for the HP- $\alpha-\mathrm{CD} / \mathrm{F} 108$ system.

By considering that $\alpha-C D$ and HP- $\alpha-C D$ exclusively interact with the PEO blocks because geometric constraints do not allow the PO units to be fitted into the CD cavity, one may state that the volume, FTIR and DSC data, on one side, and the geometric size of EO and $\mathrm{CD}$, on the other side, provide exhaustive insights to describe the structures of the complexes based on $\alpha-C D$ and HP- $\alpha-C D$. Namely, in the IC the PPO block is unbound while the PEO blocks are encapsulated into CD molecules where they are in the amorphous state. Moreover, based on the stoichiometry (Table 5) and remembering that the length of one EO unit, $\alpha-C D$ and HP- $\alpha-C D$ is $0.36,0.79$, and $1.15 \mathrm{~nm}$, respectively, one may propose different supramolecular structures for the native and the alkylated CDs. Namely, a columnar structure of $\alpha-C D$ resembling to a long cylindrical channel which includes the EO units may be depicted (Figure 10). For HP- $\alpha-C D$, the IC may be described by a polymeric structure with the PEO chains decorated with some CD molecules (Figure 10).

VIII. Surface Tension of Aqueous Copolymer/CD Mixtures. The surface tension investigation was extended to some systems (composed of F88 and HP- $\alpha-\mathrm{CD}$ or $\mathrm{HP}-\beta-\mathrm{CD}$ ) to discuss in a comprehensive manner the role played by the ICs at the interface. Preliminarily, studies were addressed with the pure components in water. As Figure 11 illustrates, the $\pi$ values 


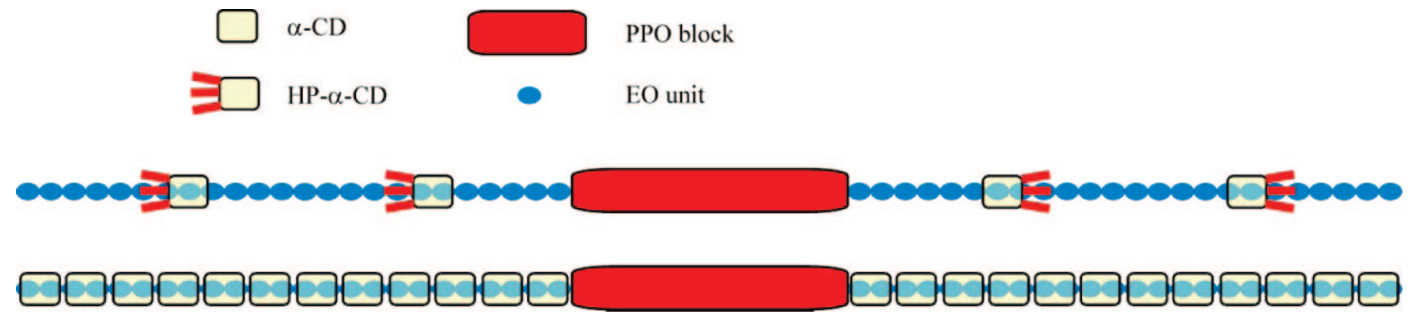

Figure 10. Schematic representation of probable supramolecular structures composed of CD and copolymer.

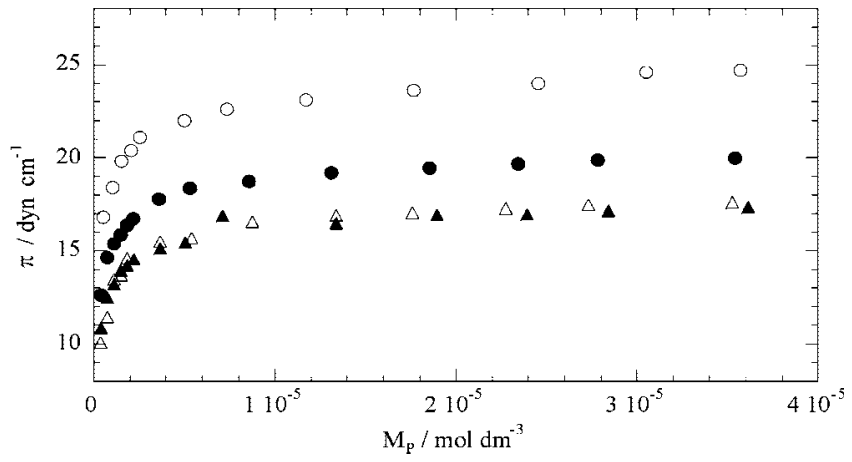

Figure 11. Surface pressure for F88 in water $(O)$, in water + HP- $\alpha-$ $\mathrm{CD}\left(\bullet, M_{\mathrm{CD}}=5 \times 10^{-4} \mathrm{~mol} \mathrm{dm}{ }^{-3} ; \Delta, M_{\mathrm{CD}}=5 \times 10^{-3} \mathrm{~mol} \mathrm{dm}^{-3}\right)$ and water $+\mathrm{HP}-\beta-\mathrm{CD}\left(\boldsymbol{\Lambda}, M_{\mathrm{CD}}=5 \times 10^{-3} \mathrm{~mol} \mathrm{dm}^{-3}\right)$ as a function of F88 molarity at $25^{\circ} \mathrm{C}$.

of F88 in water markedly increases with the copolymer molarity $\left(M_{\mathrm{P}}\right)$ in the very low composition domain. By applying the Gibbs equation to $\pi$ data it was estimated the surface concentration of F88 saturated monolayer $(\Gamma)$ value of $5.37 \times 10^{-11} \mathrm{~mol}$ $\mathrm{cm}^{-2}$ from which the area per molecule $\left(A_{\mathrm{P}}\right)$ of $3.1 \mathrm{~nm}^{2}$ molecule ${ }^{-1}$ was computed. For a comparison purpose, the $A_{\mathrm{P}}$ values of F88 in water were calculated under two conditions. One considers a random coil model ${ }^{56}$ from which the radius of gyration $\left(R_{\mathrm{g}}\right)$ is given by

$$
R_{g}=\sqrt{\frac{C_{\infty} N l^{2}}{6}}
$$

where $l$ is the monomer length $(0.36 \mathrm{~nm}), C_{\infty}$ the characteristic ratio in the limit of long chains (4.0 for PEO) and $N$ the number of monomer units $(\mathrm{PO}+\mathrm{EO}=245)$. The estimated $A_{\mathrm{P}}$ is 10 $\mathrm{nm}^{2}$ molecule ${ }^{-1}$. The second condition assumes that the PPO block is an extended cylinder the circular area of which $(0.25$ $\mathrm{nm}^{2}$ molecule ${ }^{-1}$ ) was obtained by using the volume of one cylindric PO unit ${ }^{57}$ with height of $0.36 \mathrm{~nm}$. The experimental $A_{\mathrm{P}}$ value, intermediate to those calculated, rules out the random coiling while it is consistent with the picture which describes the PEO blocks meandering into the aqueous phase and the U-shaped PPO block in the air region. Such a PPO configuration would require the $A_{\mathrm{P}}$ minimum value of $0.50 \mathrm{~nm}^{2}$ molecule ${ }^{-1}$. Of course, this situation is unreal because of the geometric constraints and repulsive interactions. Therefore, the $A_{P}$ experimental value larger than $0.5 \mathrm{~nm}^{2}$ molecule ${ }^{-1}$ fits our description. Some EO units are perhaps present at the interface according to the report ${ }^{58}$ that PEO is active at the interface.

Figure 12 illustrates that CDs in water exercise a pressure which increases in a no-linear manner with the molarity $\left(M_{\mathrm{CD}}\right)$. At fixed $M_{\mathrm{CD}}, \pi(\mathrm{HP}-\alpha-\mathrm{CD})<\pi(\mathrm{HP}-\beta-\mathrm{CD})$. From the experimental data, the $\Gamma$ values of $4.96 \times 10^{-11}$ and $4.38 \times 10^{-11}$ mol cm $\mathrm{cm}^{-2}$ for HP- $\alpha-\mathrm{CD}$ and HP- $\beta$-CD were obtained, respectively, which, in turn, provided the $A_{\mathrm{CD}}$ values of $3.3 \pm 0.1$ and $3.8 \pm 0.1 \mathrm{~nm}^{2}$ molecule ${ }^{-1}$, respectively. The small difference between the two $A_{\mathrm{CD}}$ values is ascribable to the larger

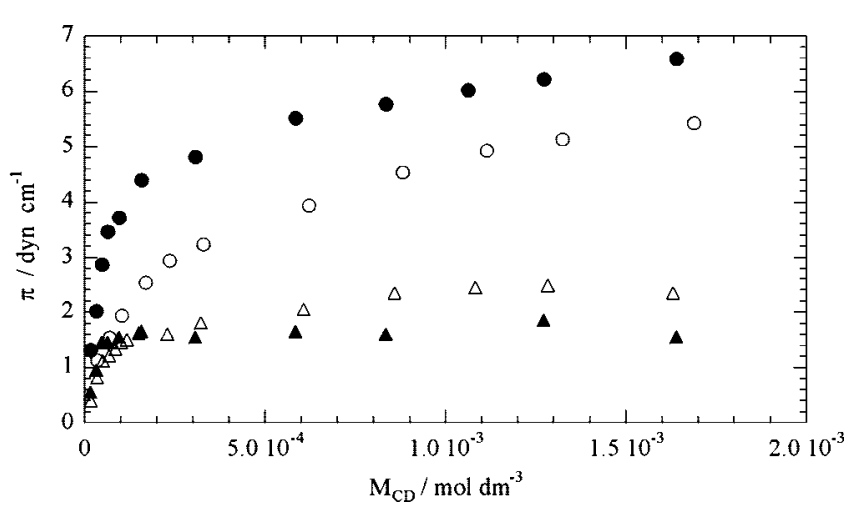

Figure 12. Surface pressure for HP- $\alpha-C D$ (empty symbols) and HP$\beta$-CD (filled symbols) in water (circles) and in water $+\mathrm{F} 8810^{-6} \mathrm{~mol}$ $\mathrm{dm}^{-3}$ (triangles) as a function of the CD molarity at $25^{\circ} \mathrm{C}$.

HP- $\beta$-CD size. These values are close to those estimated by using the external radius ${ }^{59}$ of the $\mathrm{CD}$ and the extended hydroxypropyl group $(0.36 \mathrm{~nm})$ which are 3.4 and $4.0 \mathrm{~nm}^{2}$ molecule ${ }^{-1}$ for HP- $\alpha-\mathrm{CD}$ and $\mathrm{HP}-\beta-\mathrm{CD}$, respectively. On the contrary, they are lower than those calculated for native CDs $\left(1.5\right.$ and $1.8 \mathrm{~nm}^{2}$ molecule ${ }^{-1}$ for $\alpha-C D$ and $\beta-C D$, respectively).

As concerns the copolymer $+\mathrm{CD}$ mixtures, Figure 11 shows that the addition of HP- $\alpha-C D$ to the water + F88 mixture does not alter the shape of the $\pi$ vs $M_{P}$ curve while it significantly does the $\pi$ values. The larger the $\mathrm{CD}$ amount added is the smaller $\pi$ is. The addition of $1 \times 10^{-6} \mathrm{~mol} \mathrm{dm}^{-3}$ of F88 to the aqueous HP- $\alpha-\mathrm{CD}$ or HP- $\beta$-CD solutions (Figure 12) induces a similar effect. The reduction of $\pi$ caused by adding $\mathrm{CD}$ to the aqueous F88 solution or adding F88 to the aqueous CD solutions likely reflects the desorption of the copolymer and the $\mathrm{CD}$, respectively, from the interface as a consequence of the IC formation in the bulk phase. Calculations performed using data in Table 3 show that under these experimental conditions the ICs do form in the bulk phase. It appears that the IC is not so active at the interface that is different to the behavior of the IC composed of $\alpha-C D$ and PEO. ${ }^{58}$

\section{Conclusions}

We have shown that Pluronics and cyclodextrins form inclusion complexes (ICs) soluble in water. This phenomenon was observed for all the investigated systems composed of native or alkylated CDs (with different cavity size) and copolymers having different molecular weight or hydrophilicity. The thermodynamic studies provided the association constants for IC, the stoichiometry and the volume change for the IC formation. The size of both the $\mathrm{CD}$ and the copolymer is crucial for the stability of the ICs. Surface tension investigations showed that the desorption of the species active at the interface takes place as a consequence of the ICs formation in the bulk phase. Volume, DSC, and FTIR characterization combined with geometrical information allowed to demonstrate that the native $\mathrm{CD}$ rings in the complex adopt a channel structure while the 
alkylated-CDs decorate the copolymer generating necklace-like structures. Moreover, they highlighted that the included copolymer is in the amorphous state. The ICs thermal stability depends on the nature of both the CD and the copolymer. A straightforward correlation between the behavior of ICs in water and in the solid state was drawn by using the tools provided by the thermodynamics.

Acknowledgment. The work was financially supported by MiUR (PRIN 2006, "Design of functional nanostructured systems for the restoration and the conservation of cultural heritage", prot. 2006088875_002). G.L. is grateful to the Università degli Studi di Palermo for the "Assegno di Ricerca" Fellowship. We thank Prof. L. Pellerito for giving us the opportunity to perform FTIR measurements.

Supporting Information Available: Figures showing the curves of TGA and DSC, text giving the procedure to calculate the degradation temperature, and figures showing plots for the evaluation of ICs stoichiometry. This material is available free of charge via the Internet at http://pubs.acs.org.

\section{References and Notes}

(1) Harada, A.; Li, J.; Kamachi, M. Macromolecules 1993, 26, 5698.

(2) Harada, A.; Kamachi, M. Macromolecules 1990, 23, 2821

(3) Harada, A.; Kamachi, M. Nature 1992, 356, 325.

(4) Harada, A. Supramol. Sci. 1996, 3, 19.

(5) Wenz, G.; Han, B. H.; Muller, A. Chem. Rev. 2006, 106, 782.

(6) Hunt, M. A.; Tonelli, A. E.; Balik, C. M. J. Phys. Chem. B. 2007, 111,3853 .

(7) Harada, A.; Li, J.; Kamachi, M. Nature 1994, 370, 126.

(8) Therekova, I.; De Lisi, R.; Lazzara, G.; Milioto, S.; Muratore, N. J. Therm. Anal. Calorim. 2008, 92, 285.

(9) Rekharsky, M. V.; Inoue, Y. Chem. Rev. 1998, 98, 1875.

(10) De Lisi, R.; Lazzara, G.; Milioto, S.; Muratore, N. Chemosphere 2007, 69, 1703.

(11) Dutet, J.; Malika Lahiani-Skiba, M.; Didier, L.; Jezequel, S.; Bounoure, F.; Barbot, C.; Arnaud, P.; Skiba, M. J. Incl. Phenom. Macrocycl. Chem. 2007, 57, 203.

(12) Zhao, S.-P.; Zhang, L. M.; Ma, D.; Yang, C.; Yan, L. J. Phys. Chem. B 2006, 110, 16503.

(13) Peet, J.; Rusa, C. C.; Hunt, M. A.; Tonelli, A. E.; Balik, C. M. Macromolecules 2005, 38, 537.

(14) Lo Nostro, P.; Lopes, J. R.; Cardelli, C. Langmuir 2001, 17, 4610

(15) Li, J.; Chen, B.; Wang, X.; Hong Goh, S. Polymer 2004, 45, 1777.

(16) Li, J.; Shin, I. D.; Nojima, S.; Tonelli, A. E. Polymer 2000, 41, 5871.

(17) Hasan, E. A.; Cosgrove, T.; Round, A. N. Macromolecules 2008, $41,1393$.

(18) Gaitano, G. G.; Brown, W.; Tardajos, G. J. Phys. Chem. B 1997, 101,710 .

(19) Li, J.; Li, X.; Zhou, Z.; Ni, X.; Leong, K. W. Macromolecules 2001, 34, 7236.

(20) Joseph, J.; Dreiss, C. A.; Cosgrove, T. Langmuir 2007, 23, 460.

(21) De Lisi, R.; Lazzara, G.; Milioto, S.; Muratore, N. Phys. Chem. Chem. Phys. 2008, 10, 794.

(22) Vieira, J. B.; Li, Z. X.; Thomas, R. K. J. Phys. Chem. B 2002, 106,5400 .

(23) De Lisi, R.; Lazzara, G.; Milioto, S.; Muratore, N. J. Chem. Thermodyn. 2006, 38, 1344.
(24) Loh, W. In Encyclopedia of Surface and Colloid Science, Somasundaran, P., Eds.; Taylor \& Francis: New York, 2006; p 1014.

(25) Lazzara, G.; Milioto, S.; Gradzielski, M. Phys. Chem. Chem. Phys. 2006, 8, 2299.

(26) De Lisi, R.; Gradzielski, M.; Lazzara, G.; Milioto, S.; Muratore, N.; Prevost, S. J. Phys. Chem. B 2006, 110, 25883.

(27) Lazzara, G.; Milioto, S.; Muratore, N. J. Phys. Chem. B 2008, 112, 5616.

(28) De Lisi, R.; Gradzielski, M.; Lazzara, G.; Milioto, S.; Muratore, N.; Prevost, S. J. Phys. Chem. B 2008, 112, 9328.

(29) Ikeda, T.; Lee, W. K.; Ooya, T.; Yui, N. J. Phys. Chem. B 2003 , 107, 14.

(30) Li, J.; Ni, X.; Zhou, Z.; Leong, K. W. J. Am. Chem. Soc. 2003, $125,1788$.

(31) Su, Y.; Wang, J.; Liu, H. J. Colloid Interface Sci. 2002, 251, 417.

(32) Shar, J. A.; Obey, T. M.; Cosgrove, T. Colloids Surf. A 1998, 136, 21.

(33) De Lisi, R.; Milioto, S.; Pellerito, A.; Inglese, A. Langmuir 1998, 14, 6045 .

(34) De Lisi, R.; Lazzara, G.; Milioto, S.; Muratore, N. J. Therm. Anal. Calorim. 2007, 87, 61.

(35) Wilson, L. D.; Verrall, R. E. J. Phys. Chem. B 2000, 104, 1880.

(36) De Lisi, R.; Milioto, S.; De Giacomo, A.; Inglese, A. Langmuir 1999, 15, 5014

(37) De Lisi, R.; Lazzara, G.; Milioto, S.; Muratore, N. J. Phys. Chem. B. 2003, 107, 13150 .

(38) Mwakibete, H.; Crisantino, R.; Bloor, D. M.; Wyn-Jones, E.; Holzwarth, J. F. Langmuir 1995, 11, 57.

(39) Rekharsky, M. V.; Myhew, P.; Goldberg, N.; Ross, P. D.; Yamashoji, Y.; Inoue, Y. J. Phys. Chem. B 1997, 101, 87.

(40) De Lisi, R.; Milioto, S.; Muratore, N. Langmuir 2000, 16, 4441.

(41) De Lisi, R.; Milioto, S.; Muratore, N. J. Phys. Chem. B 2002, 106, 8944

(42) De Lisi, R.; Lazzara, G.; Milioto, S.; Muratore, N.; Terekhova, I. V. Langmuir 2003, 19, 7188 .

(43) González-Gaitano, G.; Sanz-García, T.; Tardajos, G. Langmuir 1999, 15, 7963.

(44) De Lisi, R.; Lazzara, G.; Lombardo, R.; Milioto, S.; Muratore, N.; Turco Liveri, M. L. Phys. Chem. Chem. Phys. 2005, 7, 3994.

(45) Tanford, C., In The Hydrophobic Effect, 2nd ed.; J. Wiley \& Sons, New York, 1979.

(46) Okada, M.; Kamachi, M.; Harada, A. J. Phys. Chem. B 1999, 103, 2607.

(47) Fujita, H.; Ooya, T.; Yui, N. Macromol. Chem. Phys. 1999, 200, 706.

(48) Udachin, K. A.; Wilson, L. D.; Ripmeester, J. A. J. Am. Chem. Soc. 2000, 122, 12375.

(49) Kawabata, R.; Katoono, R.; Yamaguchi, M.; Yui, N. Macromolecules 2007, 40, 1011.

(50) Yei, D. R.; Kuo, S. W.; Fu, H. K.; Chang, F. C. Polymer 2005, 46, 741.

(51) Rossi, L. I.; de Rossi, R. H. Appl. Catal. A: Gen. 2004, 267, 267.

(52) Xie, D. M.; Yang, K. S.; Sun, W. X. Curr. Appl. Phys. 2007, 7S1, e15.

(53) Su, Y. C.; Che, W. C.; Chang, F. C. Polymer 2005, 46, 1617.

(54) Wei, M.; Davis, W.; Urban, B.; Song, Y.; Porbeni, F. E.; Wang, X.; White, J. L.; Balik, C. M.; Rusa, C. C.; Fox, J.; Tonelli, A. E. Macromolecules 2002, 35, 8039.

(55) Guo, C.; Liu, H.; Wang, J.; Chen, J. J. Colloid Interface Sci. 1999, $209,368$.

(56) Flory, P. J., Statistical Mechanics of Chain Molecules, Interscience: New York, 1969.

(57) De Lisi, R.; Lazzara, G.; Lombardo, R.; Milioto, S.; Muratore, N.; Turco Liveri, M. L. J. Solution Chem. 2006, 35, 659.

(58) Gargallo, L.; Vargas, D.; Leiva, A.; Radić, D. J. Colloid Interface Sci. 2006, 301, 607.

(59) Szejtli, J. Chem. Rev. 1998, 98, 1743.

JP8034924 